\title{
Novel RP-HPLC method development and validation for simultaneous estimation of metformin, voglibose and pioglitazone in bulk and triple fixed drug combinations pharmaceutical dosage form
}

\author{
Shende Mulchand A*, Budde Balkrishna R. \\ Department of Quality Assurance, Government College of Pharmacy, Kathora Naka, Amravati- 444604, India
}

\begin{abstract}
Reducing treatment complexity can be achieved through the use of single-tablet triple fixed-dose combinations of oral hypoglycemic agents. A simple, precise and accurate reverse-phase high-performance liquid chromatographic (RP-HPLC) method was developed and validated for the simultaneous determination of Metformin (MET), Voglibose (VOG) and Pioglitazone (PIO) in pharmaceutical dosage forms. Chromatographic separation was achieved on an Younglin (SK) gradient System with UV 730 D detector and Cosmosil C18 (250 x 4.6 mm, $5 \mu \mathrm{m}$ ) column, maintained at $45^{\circ} \mathrm{C}$ using $0.1 \% \mathrm{v} / \mathrm{v}$ acetonitrile: triethylamine $(30: 70, \mathrm{v} / \mathrm{v}), \mathrm{pH} 2.5 \mathrm{with}$ flow rate $0.8 \mathrm{ml} / \mathrm{min}$ with injection volume at $20 \mu \mathrm{l}$ and wavelength ultraviolet detection at $232 \mathrm{~nm}$. MET, PIO and VOG obey Beer-Lambert's law over the concentration range of 200-600 $\mu \mathrm{g} / \mathrm{ml}, 30-90$ $\mu \mathrm{g} / \mathrm{ml}$ and $0.08-0.24 \mu \mathrm{g} / \mathrm{ml}$, respectively, with regression equations $\mathrm{y}=2.021 \mathrm{x}-186.7(\mathrm{MET})\left(\mathrm{R}^{2}=0.998\right), \mathrm{y}=9.876 \mathrm{x}-202.31(\mathrm{PIO})\left(\mathrm{R}^{2}=0.999\right)$, and $y=502.3 x-17.23(V O G)\left(R^{2}=0.999\right) . \%$ RSD and recoveries were 100.57-101.60 for MET, 99.79-102.61 for PIO and 100.02-101.05 for VOG indicate good accuracy of method. The marketed formulation analyzed using developed method and mean \% amount were found $101.62,100.38$ and 98.75 for MET, PIO and VOG respectively with \% RSD values NMT 2.0\%. The developed spectrophotometric method can be employed for routine analysis of MET, VOG and PIO in bulk and tablet formulation. The developed RP-HPLC method was sensitive and selective for estimation of metformin, voglibose and pioglitazone in combined dosage form. The method was validated as per ICH guidelines.
\end{abstract}

Keywords: RP-HPLC, ICH guidelines, Metformin, Voglibose, Pioglitazone, Validation

Article Info: Received 05 Nov 2018; Review Completed 12 Dec 2018; Accepted 19 Dec 2018; Available online 15 Jan 2019

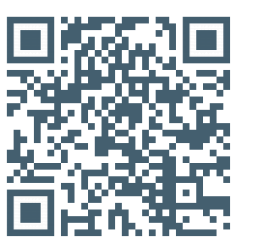

\section{Cite this article as:}

Shende MA, Budde BR, Novel RP-HPLC method development and validation for simultaneous estimation of metformin, voglibose and pioglitazone in bulk and triple fixed drug combinations pharmaceutical dosage form, Journal of Drug Delivery and Therapeutics. 2019; 9(1):30-37 DOI: http://dx.doi.org/10.22270/jddt.v9i1.2256

Mulchand A Shende, Department of Quality Assurance, Government College of Pharmacy, Kathora Naka, Amravati- 444604, India

\section{INTRODUCTION}

In diabetic mellitus treatment, combination rationales for the most commonly employed FDC products are to provide rationale drug regulatory mechanism and enhance drug therapeutic effectiveness ${ }^{1}$. Following the widespread acceptance of two drugs fixed drug combinations (FDC) for oral antidiabetic drug (OAD); Indian pharmaceutical companies have introduced triple FDC of metformin, pioglitazone and voglibose, in varying doses $^{2}$. Metformin biguanide hypoglycemic agent used in the treatment of noninsulin-dependent diabetes mellitus by improving insulin sensitivity at the muscle and liver and pioglitazone by improving adipose tissue insulin sensitivity by PPAR- $r$ agonism. Voglibose is an $\alpha$-glucosidase inhibitor that acts by reducing the postprandial blood glucose by regulating glucose absorption. Studies have shown the effectiveness of both these combinations of triple OAD. Fixed drug combinations has been associated with improved compliance and improved glycemic control ${ }^{3}$. Reducing the number of medication diminishes the complexity of the regimen, so that superior patient adherence is anticipated with combination products. In general, these kinds of multicomponent dosage forms are useful for effective therapy and augment patient compliance. Method developed can be conveniently used for quality control and routine determination of drug in pharmaceutical preparation in pharmaceutical industry. Metformin, chemically is 3(diaminomethylidene)-1, 1-dimethylguanidine (figure1a). Metformin improves glycemic control by improving insulin sensitivity and decreasing intestinal absorption of glucose ${ }^{4}$. Voglibose is chemically valiolamine derivative $(1 \mathrm{~S}, 2 \mathrm{~S}, 3 \mathrm{R}, 4 \mathrm{~S}$, 5S)-5-(1, 3-dihydroxypropan-2-ylamino)-1-(hydroxymethyl) cyclohexane-1, 2, 3, 4-tetrol and inhibitor of $\alpha$-glucosidase with antihyperglycemic activity (fig. 1b). Voglibose inhibits $\alpha$-glucosidase, an enteric enzyme found in the brush border of the small intestines that hydrolyzes oligosaccharides and disaccharides into glucose and other monosaccharides. This prevents the breakdown of larger carbohydrates into glucose and decreases the rise in postprandial blood glucose levels 5 . 


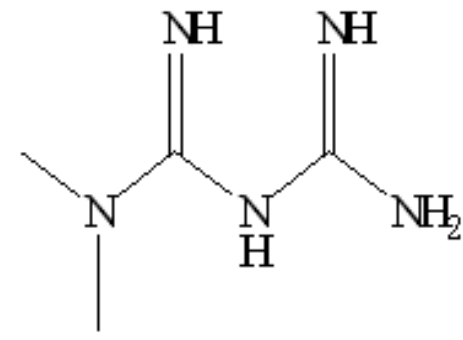

(a)

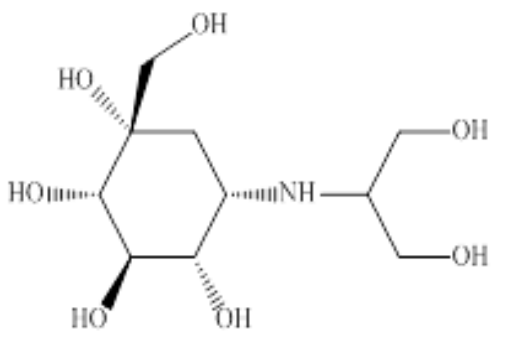

(b)

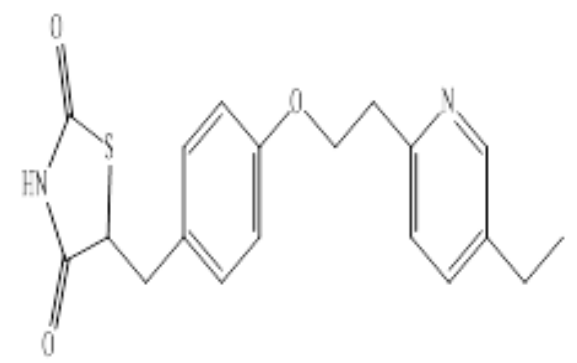

(c)

Figure 1: Chemical structure of (a) Metformin, (b) Voglibose and (c) Pioglitazone

Pioglitazone is 5-[[4-[2-(5-ethylpyridin-2-yl) ethoxy] phenyl] methyl]-1, 3-thiazolidine-2, 4-dione and it is selective agonists for the nuclear peroxisome proliferator-activated $\gamma$ receptor (PPAR $\gamma$ ) which enhances the transcription of several insulin responsive genes (figure1c) ${ }^{5}$. The combination is used for the treatment of diabetes mellitus and particularly demonstrated significant decrease in glucose level in diabetes. The combination of Metformin (MET), Voglibose (VOG), and Pioglitazone (PIO) is widely available in the market for the treatment of diabetes mellitus. Analysis is important in every product but it is vital in medicines as it involves life. Analytical methods are necessary to assure the identity, strength, quality, purity and bioavailability of drug product and stability ${ }^{6}$. The assurance of quality is achieved through analysis of drug product. Reverse phase chromatography is usually a method of first choice because of convenience, wide applicability and good understanding of operating principles. In the reverse- phase HPLC; the relative polarities of the stationary and mobile phases are opposite to those in normal HPLC i.e. the stationary phase is less polar than the mobile phase and consequently the solutes are eluted in order of their decreasing polarities. These phases are prepared by treating surface silanol groups of silica with orthogonochlorosilane reagent. So the reverse phase HPLC is highly preferred for the pharmaceutical compounds. Literature survey revealed that there are a number of analytical techniques, such as RPHPLC, HPLC and UV spectrophotometric methods have been reported for this combination in individually or in combination of listed two drugs. The RP-HPLC methods were reported by Lakshmi $\mathrm{K}$ et al., ${ }^{7}$ Sonia $\mathrm{K}$ et al. ${ }^{8}$ and UV spectroscopy were reported by Sujana K et al. ${ }^{9}$ and Raj N et al. ${ }^{10}$. There are no any analytical methods reported previously for the simultaneous estimation of voglibose, pioglitazone and metformin in multicomponent in dosage form. There is need to develop accurate method for the concurrent determination of these drugs in combined dosage forms. Therefore, it was aimed to develop a simple, accurate, sensitive and reproducible method for triple dose combinations voglibose, pioglitazone and metformin in combined dosage forms by RP-HPLC.

\section{MATERIALS AND METHODS}

\section{Chemicals and reagents}

Active pharmaceutical ingredients of Metformin, Pioglitazone and Voglibose were received as gift sample from Macloids Pharmaceuticals Ltd. Gujarat, India. Triple distilled water from Milliq, acetonitrile and methanol of HPLC grade were procured from Merck and orthophosphoric acid of AR grade obtained from Fisher scientific. The commercial sample containing Voglibose $(0.2 \mathrm{mg})$, Metformin (500 $\mathrm{mg}$ ) and Pioglitazone $(7.5 \mathrm{mg})$ was purchased from local market of D-Bose MP275 brand of
SALUD Care (I) Pvt. Ltd. Khanapur, Roorkee. All the chemicals and reagents were used of analytical grade.

\section{Instrumentation and chromatographic conditions}

Liquid chromatographic separation was achieved using Younglin (SK) gradient system with auto injector and UV 730 D detector with column cosmosil $\mathrm{C}_{18}(4.6 \times 250 \mathrm{~mm}, 5 \mu \mathrm{m})$ with Autochro-3000 software and maintained at $45^{\circ} \mathrm{C}$. UVVisible spectrophotometer with special bandwidth of $2 \mathrm{~mm}$ and $10 \mathrm{~mm}$ and matched quartz was be used for measuring absorbance for MET, VOG and PIO solutions. The mobile phase consisting mixture of acetonitrile: $0.1 \% \mathrm{OPA}, \mathrm{pH}$ adjusted to 2.5 with triethylamine in the ratio $30: 70 \mathrm{v} / \mathrm{v}$. and filtered through $0.45 \mu \mathrm{m}$ membrane filter and diluent used was methanol of HPLC grade for common solvent for standard and sample preparation. The column was maintained at room temperature $\left(25^{\circ} \mathrm{C}\right)$ and the flow rate was $0.8 \mathrm{ml} / \mathrm{min}$. The preceding to inject the solutions, the column is stabilized for 30 minutes with the mobile phase flowing through the system. $20 \mu \mathrm{l}$ of sample was injected in HPLC at UV-Visible at a detective wavelength of $232 \mathrm{~nm}$. Under defined experimental conditions; all the peaks were well resolved and free from tailing with good resolution.

\section{Selection of diluent and Preparation Standard and Sample}

Solubility studies were done by dissolving drugs in solvents like water and methanol. It was observed that Metformin (MET) was freely soluble in water and methanol but Voglibose (VOG) and Pioglitazone (PIO) were sparingly soluble in water forms turbidity and freely soluble in methanol therefore methanol was selected as a common solvent.

Accurately weighed and transferred $500 \mathrm{mg}$ of MET, $7.5 \mathrm{mg}$ of PIO and $0.2 \mathrm{mg}$ of VOG standards into a $100.0 \mathrm{ml}$ clean dry volumetric flask. Then a small amount of diluent was added and the flask was sonicated for $30 \mathrm{~min}$ and diluted up the mark with diluent to obtained final concentrations of MET, PIO and VOG were $5000 \mu \mathrm{g} / \mathrm{ml}, 75 \mu \mathrm{g} / \mathrm{ml}$ and $2 \mu \mathrm{g} / \mathrm{ml}$, respectively. From the above stock solutions, $1 \mathrm{ml}$ was pipette out to a $10 \mathrm{ml}$ volumetric flask and the final volume was made up with diluent to obtain final concentrations of $500 \mu \mathrm{g} / \mathrm{ml} \mathrm{MET}, 7.5 \mu \mathrm{g} / \mathrm{ml} \mathrm{PIO}$, and $0.2 \mu \mathrm{g} / \mathrm{ml} \mathrm{VOG}$.

\section{Method development and optimization}

For selection of column, a spiked sample of MET was prepared with mixture of VOG and PIO, and injected HPLC system with different columns. The required system suitability criterion was obtained using cosmosil $\mathrm{C}_{18}$ $(4.6 \times 250 \mathrm{~mm}), 5 \mu \mathrm{m}$ column.

\section{Method Validation}


The analytical method was validated as per ICH guidelines with respect to parameters such as linearity, accuracy, precision, and robustness, limit of detection and limit of quantification 11,12 .

\section{Linearity}

Linearity of this method was assessed by linear regression analysis, calculated by least square method. A series of solutions were prepared from by diluting the stock solutions of MET (200-600 $\mu \mathrm{g} / \mathrm{ml})$, PIO (30-90 $\mu \mathrm{g} / \mathrm{ml})$ and VOG (0.08$0.24 \mu \mathrm{g} / \mathrm{ml}$ ), with mobile phase. $20 \mu \mathrm{l}$ of mixture of these solutions was injected into the HPLC system, and the peak area of each of the drug was noted from the chromatogram.

\section{Accuracy}

For the accuracy study, 10 tablets were weighed and powdered. The accuracy of the assay method was evaluated in triplicate at three concentration levels $(80,100$, and $120 \%)$, and the percentage recoveries were calculated. Standard addition and recovery experiments were conducted to determine the accuracy of the method for the quantification of MET, PIO and VOG, respectively; in the drug product and the $\%$ RSD was calculated.

\section{System Suitability}

An accurately weighed quantity of MET working standard about $500 \mathrm{mg}$, PIO $7.5 \mathrm{mg}$ and VOG $0.2 \mathrm{mg}$ where transferred into $100.0 \mathrm{ml}$ volumetric flask about $100 \mathrm{ml}$ of methanol was added to each of volumetric flask and sonicated to dissolve the drug the solution was cooled to the room temperature and made up to the mark with methanol to obtained the final concentrations of $5000 \mu \mathrm{g} / \mathrm{ml} \mathrm{MET,} 75 \mu \mathrm{g} / \mathrm{ml} \mathrm{PIO} \mathrm{and} 2$ $\mu \mathrm{g} / \mathrm{ml}$ VOG. Pipette out $1.0 \mathrm{ml}$ of these solutions into $10.0 \mathrm{ml}$ volumetric flask separately and diluted up to the mark with mobile phase to obtain $500 \mu \mathrm{g} / \mathrm{ml} \mathrm{MET,} 7.5 \mu \mathrm{g} / \mathrm{ml} \mathrm{PIO} \mathrm{and}$ $0.2 \mu \mathrm{g} / \mathrm{ml}$ VOG. Filtered mobile phase was allowed to equilibrate with stationary phase until steady baseline was obtained. A $20 \mu$ l standard drugs solution were injected in three replicates and the system suitability parameters were recorded.

\section{Precision}

Precision is the measure of how close the data values are to each other for a number of measurements under the same analytical conditions. Precision of method was evaluated by intraday and interday variation studies. Intraday and interday variations were determined by analyzing three different solutions of MET, PIO and VOG within the same day and three different days over a period of week. Intraday precision was estimated by analyzing $200 \mu \mathrm{g} / \mathrm{ml}, 400 \mu \mathrm{g} / \mathrm{ml}$, $600 \mu \mathrm{g} / \mathrm{ml}$ of MET, $30 \mu \mathrm{g} / \mathrm{ml}, 60 \mu \mathrm{g} / \mathrm{ml}, 90 \mu \mathrm{g} / \mathrm{ml} \mathrm{PIO} \mathrm{and}$ $0.08 \mu \mathrm{g} / \mathrm{ml}, 0.16 \mu \mathrm{g} / \mathrm{ml}$ and $0.24 \mu \mathrm{g} / \mathrm{ml}$ of VOG for three times within the same day. Interday precision was estimated by analyzing above mentioned concentrations of three drugs for three different days over a period of week and the \% RSD was calculated.

\section{Limit of detection and Limit of quantification}

The LOD and LOQ are both are calculated based on mean standard deviation and slope of the calibration curve at the levels approaching the LOD and LOQ. ICH guidelines describe several approaches to determine the detection and quantitation limits. The LOD and LOQ are the lowest level and lowest concentration of the analyte respectively in a sample that would yield signal to noise ratio of 3.3 for LOD and 10 for LOQ. These are determined from the standard deviation of the peak response and the slope of the calibration curve.

\section{Robustness}

Robustness was tested using so called factor 'one factor at a time' method. The factors evaluated were mobile phase composition, flow rate, wavelength. The robustness was evaluated by changing the flow rate by $\pm 10 \%$, by changing the wavelength by $\pm 1 \mathrm{~nm}$ and changing concentration of mobile phase $\pm 1 \%$.

\section{Analysis of commercial formulations}

Twenty tablets of commercial available D-Bose MP 275 each containing $500 \mathrm{mg}$ of Metformin $7.5 \mathrm{mg}$ of Pioglitazone and $0.2 \mathrm{mg}$ of Voglibose were procured from the local medical store and powder equivalent to $500 \mathrm{mg}$ of MET, $7.5 \mathrm{mg}$ of PIO and $0.2 \mathrm{mg}$ of VOG was accurately weighed and transferred to a $100 \mathrm{ml}$ volumetric flask. The contents were thoroughly sonicated with diluent and filtered through 0.45 $\mu \mathrm{m}$ filter. The extracted solution was further diluted with mobile phase as per the requirement and $20 \mu$ of each brand was injected in three replicates as per chromatographic condition into the HPLC system and the peak areas of the three drugs were noted from the chromatogram obtained and the percentage recovery was calculated from the linear regression equation. Amount of drug present in average weight of tablet as per the labeled claim was calculated using following formula:

$$
\% \text { label claim }=\frac{A s p}{A s t} \times \frac{D s t}{D s p} \times \frac{A}{L c} \times P
$$

Where, At = Area count for sample solution, As = Area count for standard solution, Ds = Dilution factor for standard, Dt = Dilution factor for sample, Lc = Label claim and A = Average weight.

Amount of drugs was calculated using formula;

$$
\mathrm{E}_{\mathrm{w}}=\frac{\mathrm{A}_{\mathrm{u}}}{\mathrm{A}_{\mathrm{s}}} \times \mathrm{C}_{\mathrm{s}} \times \mathrm{d}
$$

Where, $E_{w}=$ drug estimated in sample weight $(\mathrm{mg}), \mathrm{C}_{\mathrm{s}}=$ concentration of standard $(\mu \mathrm{g} / \mathrm{ml}), A_{u}=$ area of unknown, $A_{s}=$ area of standard and $\mathrm{D}=$ dilution factor.

\section{RESULTS AND DISCUSSION}

Solubility studies revealed that Metformin (MET) was freely soluble in water and methanol, but Voglibose (VOG) and Pioglitazone (PIO) were sparingly soluble in water forms turbidity and freely soluble in methanol. Therefore, methanol was selected as a common solvent for proposed method. Optimization of mobile phase can be started only after a reasonable chromatogram has been obtained.

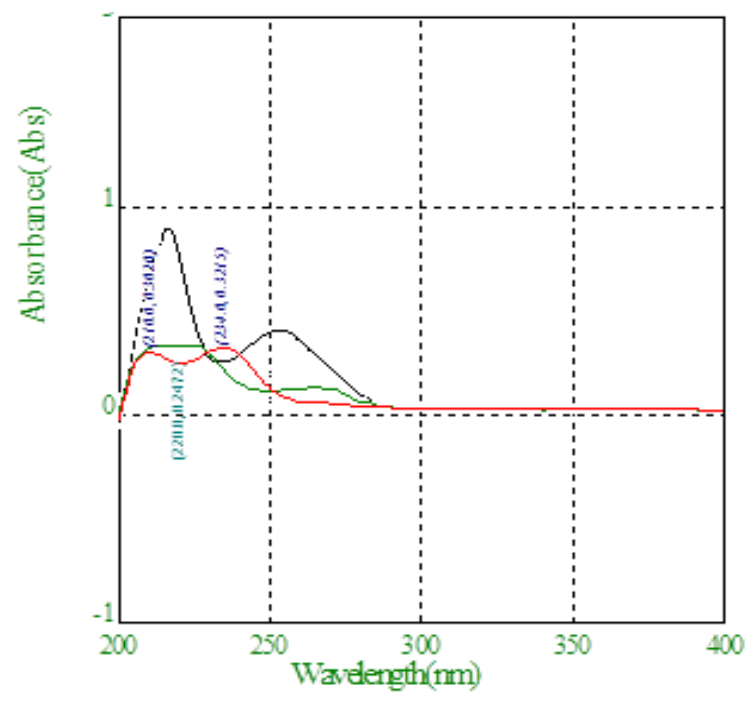

Figure 2: Overlain Spectra of MET, PIO and VOG 
A reasonable chromatogram means that more or less symmetrical peaks on the chromatogram after the detection of all the compounds. By slight change of the mobile phase composition, the position of the peaks can be predicted within the range of investigated changes. An optimized chromatogram was the one in which all the peaks are symmetrical and well separated in less run time. The mobile phase was selected on the basis of best separation, peak purity index, peak symmetry, theoretical plate etc. So, numbers of trials were taken for the selection of mobile phase. After number of trials, a mixture of Acetonitrile: 0.1\% OPA $(0.1 \%$ OPA in $100 \mathrm{ml})(30: 70, \mathrm{v} / \mathrm{v}) \mathrm{pH}$ adjusted to 2.5 with triethylamine was selected as a mobile phase. The working standard solutions of MET, VOG and PIO were scanned in the entire UV range of $400-200 \mathrm{~nm}$ to get absorbance spectrum and overlay spectra of MET, VOG and PIO are shown in figure 2 .

The common wavelength of absorption was found to be 232 $\mathrm{nm}$. So the wavelength selected for the determination of MET, PIO and VOG was $232 \mathrm{~nm}$. The different mobile phase flow rates $(0.7,0.8,1.0 \mathrm{ml} / \mathrm{min})$ were investigated. The optimum flow rate for which the column plate number $(\mathrm{N})$ was maximum, with the best resolution between all components and with a short run time was selected. A typical chromatogram of MET, VOG and PIO sample is shown in figure 3.

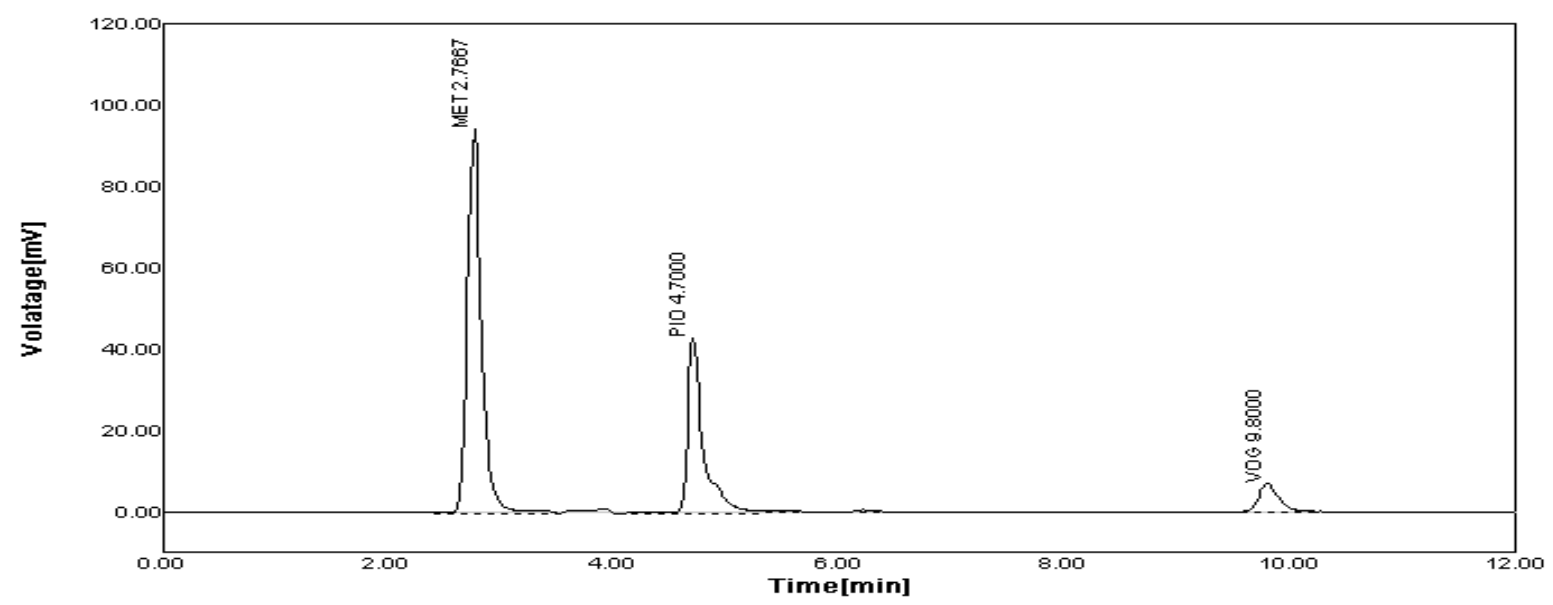

Figure 3: Chromatogram of MET, PIO and VOG using acetonitrile: 0.1\% OPA

A simple, precise, accurate, and robust RP-high performance liquid chromatographic method was developed and validated for the simultaneous determination of MET, VOG and PIO in pharmaceutical dosage forms (Tablets). When method development and optimization is complete, it is necessary to accomplish method validation. For validation of analytical method, the guidelines of the international conference on the harmonization of technical requirements for the registration of pharmaceuticals for human use has recommended validation characteristics including system suitability, accuracy (\% recovery), linearity, precision were investigated. Calibration curves were prepared peak area ratios and concentrations were subjected to least square linear regression analysis to calculate the calibration equations and correlation coefficients. Beer-Lambert's law was obeyed over the concentration range $200-600 \mu \mathrm{g} / \mathrm{ml}$ for MET, $30-90 \mu \mathrm{g} / \mathrm{ml}$ for PIO and $0.08-0.24 \mu \mathrm{g} / \mathrm{ml}$ for VOG were shown in figure 4 . The mean regression equations were found as $\mathrm{R}^{2}=0.998, \mathrm{y}=2.021 \mathrm{x}-186.7$ for MET, $\mathrm{R}^{2}=0.999$, $y=9.876 x-202.31$ for PIO and $R^{2}=0.999, y=502.3 x-17.23$ for
VOG where "y" is the peak area ratio of drugs, "a" is the slope, " $b$ " is the intercept and " $x$ " is the concentration of the measured solution in $\mu \mathrm{g} \mathrm{ml}^{-1}$. The result shows that there is an excellent correlation between the peak area ratios and the concentrations of drugs in the range tested. Regression equation and linearity range is depicted in table 1 . Accuracy is the closeness of the best result obtained by the method to the true value. The concentration recovered should be within $\pm 2 \%$ to the true value. Accuracy of the developed method was confirmed by recovery study as per ICH norms at three different concentration levels of $80 \%, 100 \%$, and $120 \%$. This is performed on the basis of recovery studies by standard addition method. Standard solutions of pure drugs (MET, PIO \& VOG) were added in different levels i.e. 80\%, $100 \%, 120 \%$. The $\%$ recovery of the added standard to the assay samples was calculated the average \% recoveries obtained as 100.57-101.60 for MET, 99.79-102.61 for PIO and 100.02-101.05 for VOG indicate good accuracy of the method.

Table 1: Standard Calibration curves of MET, PIO and VOG

\begin{tabular}{|c|c|c|c|c|c|c|}
\hline \multirow{2}{*}{ Sr. No. } & \multicolumn{2}{|c|}{ Concentration $\mathbf{~ i n g} / \mathbf{m l}$} & \multicolumn{3}{c|}{ Peak Area } \\
\cline { 2 - 7 } & MET & PIO & VOG & MET & PIO & VOG \\
\hline 1 & 200 & 30 & 0.08 & $224.20 \pm 0.62$ & $95.46 \pm 0.72$ & $21.97 \pm 0.06$ \\
\hline 2 & 300 & 45 & 0.12 & $415.71 \pm 0.05$ & $235.80 \pm 1.07$ & $43.54 \pm 0.37$ \\
\hline 3 & 400 & 60 & 0.16 & $609.81 \pm 5.55$ & $394.09 \pm 1.87$ & $63.55 \pm 0.09$ \\
\hline 4 & 500 & 75 & 0.2 & $845.35 \pm 2.75$ & $540.39 \pm 1.68$ & $83.93 \pm 0.21$ \\
\hline 5 & 600 & 90 & 0.24 & $1015.24 \pm 7.76$ & $684.45 \pm 5.10$ & $101.27 \pm 1.72$ \\
\hline Slope & 2.021 & 9.876 & 502.3 & & & \\
\hline Intercept & 186.72 & 202.31 & 17.23 & & & \\
\cline { 1 - 3 } $\begin{array}{c}\text { Correlative } \\
\text { Coefficient (R }\end{array}$ & 0.998 & 0.999 & 0.999 & & & \\
\end{tabular}



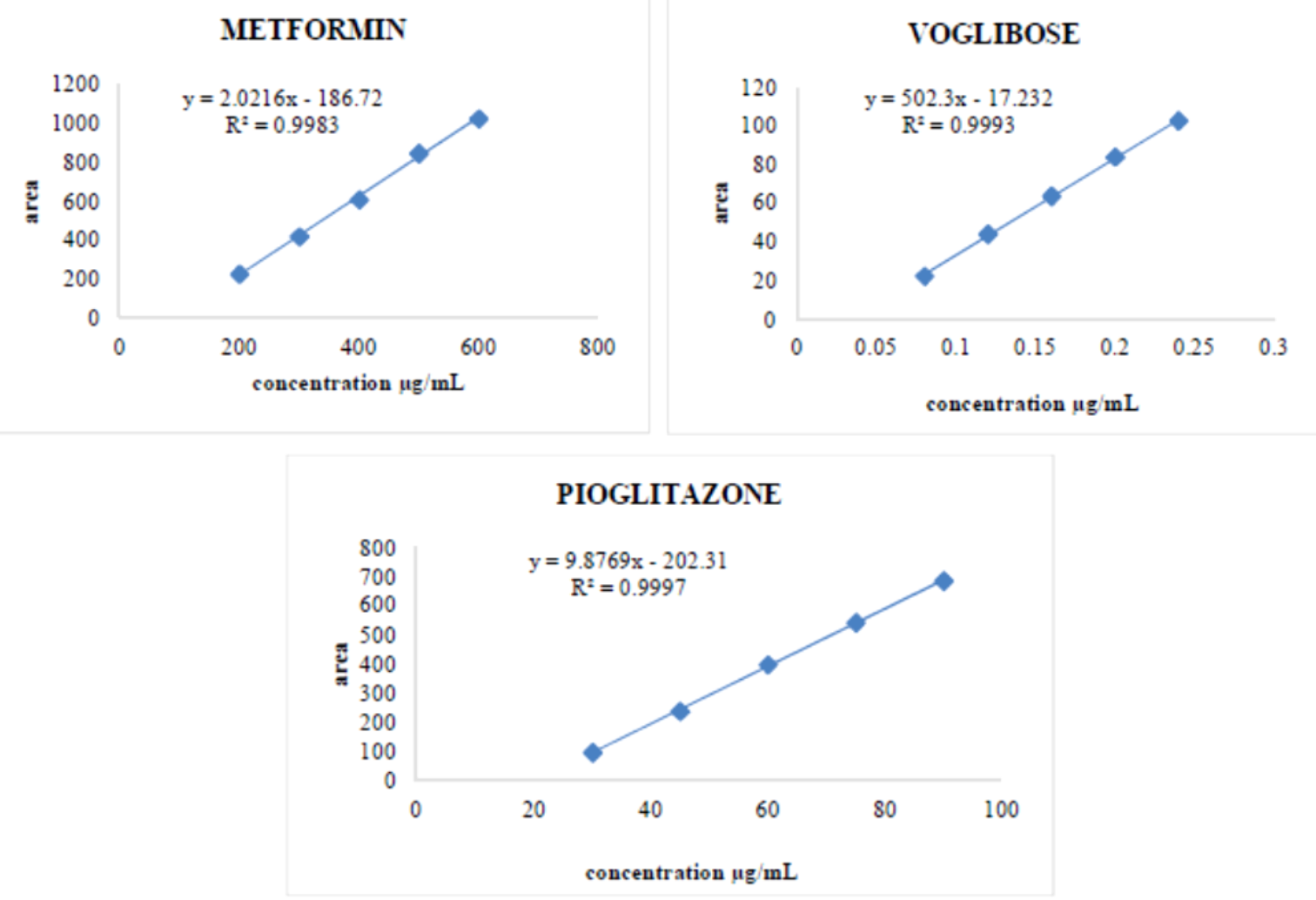

Figure 4: Standard calibration curve of MET, VOG and PIO

The \% mean recoveries were found with \% RSD less than 2 for MET, PIO and VOG which fully agrees with system suitability. The data was given in the table 2 and chromatograms are shown in figure 5(a), (b), and (c). This showed that, the proposed HPLC method for the determination of MET, PIO and VOG was found to be sufficiently accurate.

Table 2: Accuracy results of MET, PIO and VOG by RP-HPLC

\begin{tabular}{|c|c|c|c|c|c|}
\hline Sample & $\begin{array}{c}\text { Amount of Added } \\
(\mu \mathrm{g} / \mathrm{ml})\end{array}$ & $\begin{array}{c}\text { Amount recovered } \\
(\mu \mathrm{g} / \mathrm{ml})\end{array}$ & $\begin{array}{c}\text { Recovery } \\
(\%)\end{array}$ & \% RSD & $\begin{array}{l}\text { Mean \% } \\
\text { recovery }\end{array}$ \\
\hline \multirow{3}{*}{ MET } & 160 & $162.573 \pm 0.876$ & $101.6 \pm 0.55$ & 0.54 & \multirow{3}{*}{0.476} \\
\hline & 200 & $200.393 \pm 0.9603$ & $100.19 \pm 0.96$ & 0.48 & \\
\hline & 240 & $241.38 \pm 1.001$ & $100.57 \pm 0.42$ & 0.41 & \\
\hline \multirow{3}{*}{ PIO } & 24 & $24.06 \pm 0.807$ & $99.83 \pm 0.44$ & 0.82 & \multirow{3}{*}{1.106} \\
\hline & 30 & $30.7833 \pm 0.473$ & $102.61 \pm 1.58$ & 1.54 & \\
\hline & 36 & $35.896 \pm 0.345$ & $99.73 \pm 0.96$ & 0.96 & \\
\hline \multirow{3}{*}{ VOG } & 0.064 & $0.064 \pm 0.001$ & $100.19 \pm 1.33$ & 1.32 & \multirow{3}{*}{1.2} \\
\hline & 0.08 & $0.08 \pm 0.001$ & $100.02 \pm 1.27$ & 1.27 & \\
\hline & 0.096 & $0.097 \pm 0.001$ & $101.05 \pm 1.03$ & 1.01 & \\
\hline
\end{tabular}

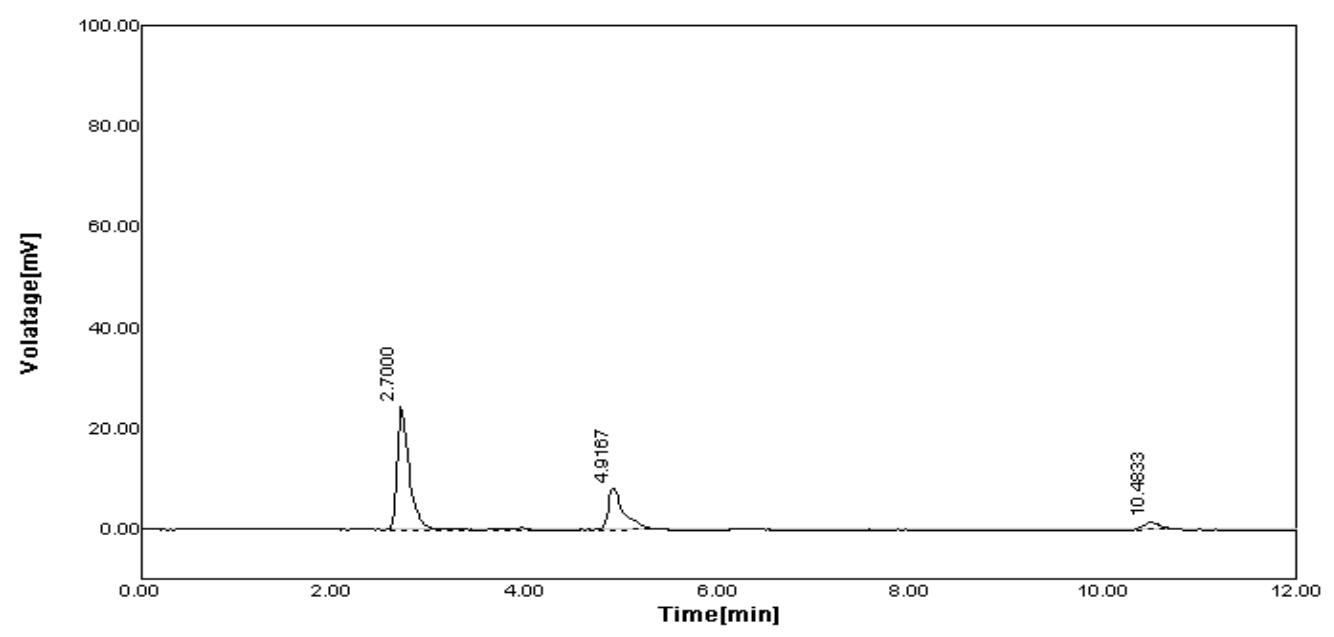

Figure 5(a): Accuracy 80\% chromatogram of MET, PIO and VOG 


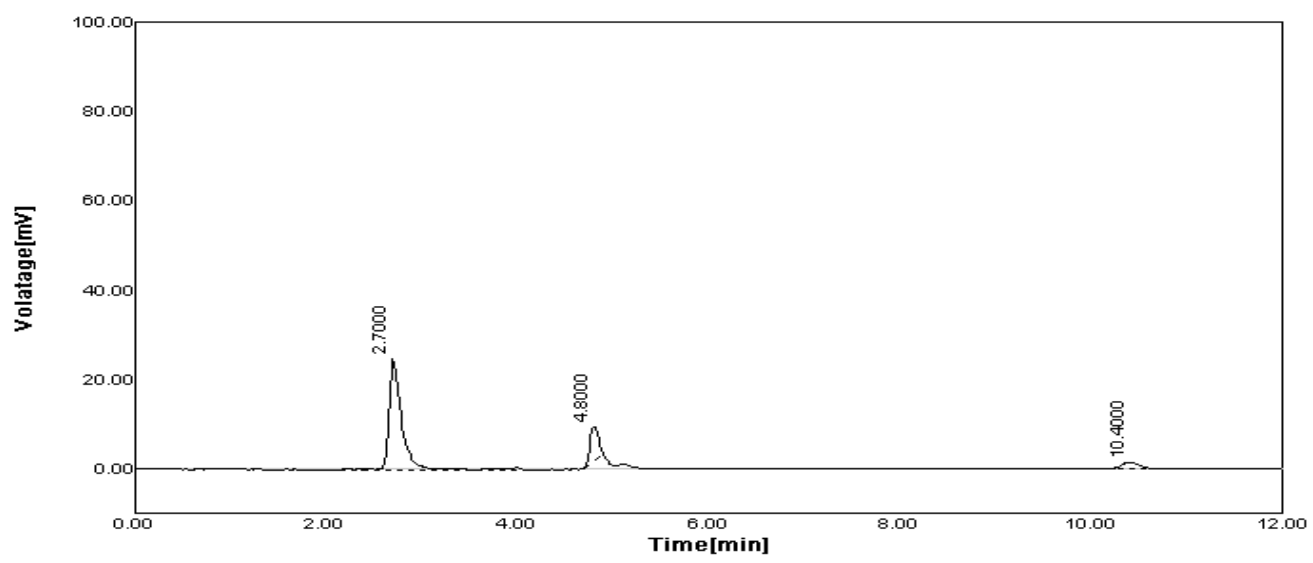

Figure 5(b): Accuracy 100\% chromatogram of MET, PIO and VOG

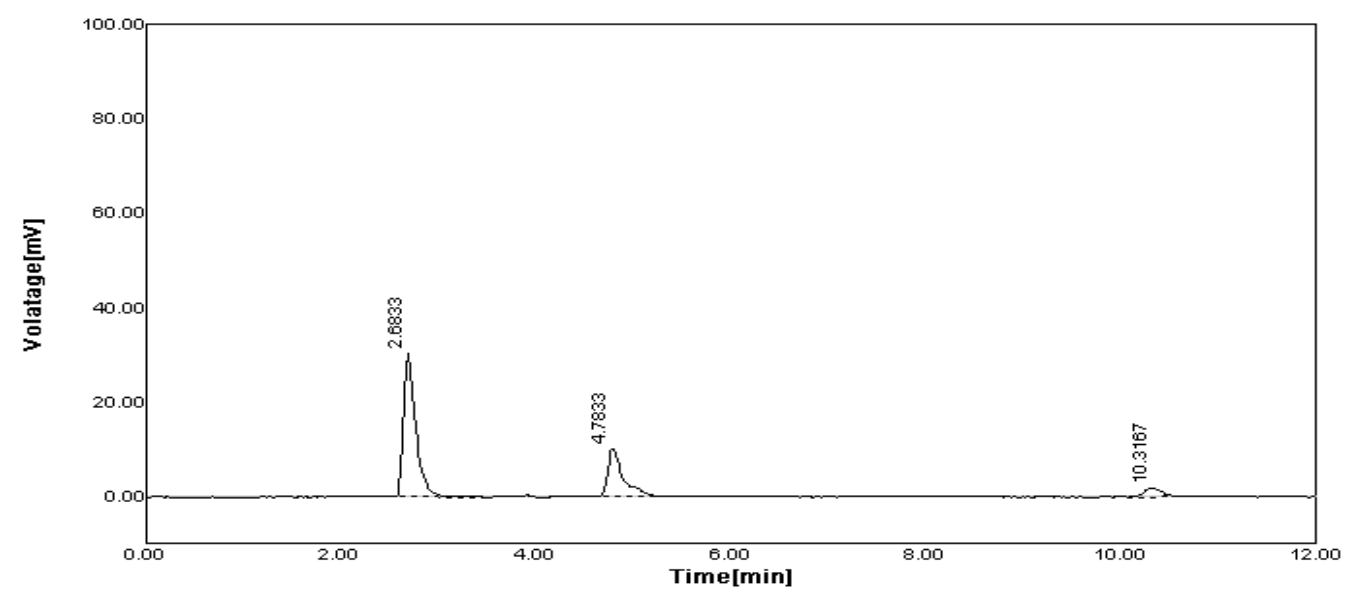

Figure 5(c): Accuracy 120\% chromatogram of MET, PIO and VOG

System suitability is a Pharmacopoeial requirement and is used to verify, whether the resolution and reproducibility of the chromatographic system are adequate for analysis to be done. The tests were performed by collecting data from three replicate Injections of standard solutions. All the parameters of system suitability were observed within the limits for MET (table 3).

Table 3: System Suitability Test for MET, PIO and VOG

\begin{tabular}{|c|c|c|c|c|c|c|}
\hline Sr. No & Drug & $\begin{array}{c}\text { Concentration } \\
(\boldsymbol{\mu g} / \mathbf{m l})\end{array}$ & Peak area & Amount found & $\begin{array}{c}\text { \% Amount } \\
\text { found }\end{array}$ & \% RSD \\
\hline 1 & MET & 200 & $226.71 \pm 0.33$ & $204.55 \pm 0.16$ & $102.27 \pm 0.083$ & 0.081 \\
\hline 2 & PIO & 30 & $96.40 \pm 0.75$ & $30.24 \pm 0.075$ & $100.79 \pm 0.25$ & 0.24 \\
\hline 3 & VOG & 0.08 & $22.83 \pm 0.11$ & $0.0797 \pm 0.00015$ & $99.66 \pm 0.215$ & 0.216 \\
\hline
\end{tabular}

The precision of an analytical method is usually expressed as the standard deviation or relative standard deviation (Coefficient of variation) of series of measurements. The sample solution was analyzed by injecting three times into the HPLC system as per test procedure and record the retention time and peak. Average retention times for MET, PIO and VOG were 2.74, 4.82 and 10.10 min, respectively. The results were given in table 4.

Table 4: Precision data for MET, PIO and VOG

\begin{tabular}{|c|c|c|c|c|c|}
\hline \multirow{3}{*}{ Drug } & \multirow{2}{*}{$\begin{array}{c}\text { Amount Taken } \\
(\boldsymbol{\mu g} / \mathbf{m l})\end{array}$} & \multicolumn{2}{|c|}{ Intraday [n= 3] } & \multicolumn{2}{c|}{ Interday [n= 3] } \\
\cline { 3 - 7 } & 200 & Amount Found & \% RSD & Amount Found & \% RSD \\
\hline \multirow{3}{*}{ MET } & 400 & 203.21 & 1.27 & 202.53 & 1.56 \\
\cline { 2 - 7 } & 600 & 403.24 & 1.04 & 404.37 & 0.39 \\
\hline \multirow{3}{*}{ PIO } & 30 & 596.47 & 0.3 & 596.94 & 0.36 \\
\cline { 2 - 7 } & 60 & 30.12 & 0.52 & 30.14 & 0.45 \\
\hline \multirow{3}{*}{ VOG } & 90 & 60.7 & 0.23 & 90.04 & 0.16 \\
\cline { 2 - 7 } & 0.08 & 89.9 & 0.078 & 0.078 & 0.71 \\
\cline { 2 - 7 } & 0.16 & 0.161 & 1.52 & 0.159 & 1.94 \\
\hline
\end{tabular}


Reproducibility in retention time and peak area is seen in both intra and inter day precision studies with a \% RSD (NMT than 2\%) for both retention time and peak area which is in agreement with system suitability. Therefore, the proposed HPLC method for the determination of MET, PIO and VOG in a tablet was found to be sufficiently precise. To ensure the insensitivity of the RP-HPLC method to minor changes in the experimental conditions it is important to demonstrate robustness of the method. Robustness was done by minor deliberate changes in chromatographic conditions and retention time of MET, PIO and VOG were noted. The factors selected were flow rate, mobile phase and temperature and the results remained unaffected. Ruggedness of method was checked by using different instruments. The relative standard deviation of the results obtained from different instruments was $<2.0 \%$. The results were given in table 5 . None of the modifications caused a significant change in the resolution between the drugs and peak area RSD, tailing factor, peak width or theoretical plates. The results of assay of test solution were not affected by varying the conditions. They fully agree with the results obtained under original conditions. The \% RSD for (retention time, peak area and \% amount found) was not more than $2 \%$ for MET, PIO and VOG. LOD and LOQ were performed on samples containing concentration of analyte, based on calibration curve method. Standard solution of MET, VOG and PIO were injected in six replicates. Average peak area of six analyte was plotted against concentration.LOD and LOQ were calculated. The LOD and LOQ were found to be $5.45 \mu \mathrm{g} / \mathrm{ml}, \quad 0.93 \mu \mathrm{g} / \mathrm{ml}, \quad 0.0032 \mu \mathrm{g} / \mathrm{ml}$ and $16.52 \mu \mathrm{g} / \mathrm{ml}$, $2.83 \mu \mathrm{g} / \mathrm{ml}, 0.0097 \mu \mathrm{g} / \mathrm{ml}$ for MET, PIO and VOG respectively. The observations and results obtained for each of parameters like, accuracy, precision, linearity, robustness lies well within the acceptance criteria. So the proposed method was simple, accurate, linear, precise, robust and used for estimation of drugs.

Table 5: Robustness data of MET, PIO and VOG

\begin{tabular}{|c|c|c|c|c|c|c|c|}
\hline \multirow{2}{*}{ Sr. No. } & \multirow{2}{*}{ Robustness condition } & \multicolumn{2}{|c|}{ MET } & \multicolumn{2}{c|}{ PIO } & \multicolumn{2}{c|}{ VOG } \\
\cline { 3 - 8 } & & Area & \% RSD & Area & \% RSD & Area & \% RSD \\
\hline 1 & Flow minus (0.7 ml) & $448.8 \pm 1.51$ & 0.34 & $158.74 \pm 1.79$ & 1.13 & $39.57 \pm 0.76$ & 1.91 \\
\hline 2 & Flow Plus $(0.9 \mathrm{ml})$ & $365.47 \pm 0.99$ & 0.27 & $173.47 \pm 0.88$ & 0.51 & $35.18 \pm 0.66$ & 1.89 \\
\hline 3 & Mobile phase minus (29+71) & $468.7 \pm 1.77$ & 0.38 & $216.4 \pm 1.46$ & 0.68 & $46.2 \pm 0.66$ & 1.44 \\
\hline 4 & Mobile phase Plus (31+69) & $418.42 \pm 1.55$ & 0.37 & $167.65 \pm 2$ & 1.19 & $44.53 \pm 0.54$ & 1.21 \\
\hline 5 & Wavelength minus (231 nm) & $431.8 \pm 2.32$ & 0.54 & $163.1 \pm 1.35$ & 0.83 & $34.4 \pm 0.67$ & 1.95 \\
\hline 6 & Wavelength Plus (233 nm) & $287.24 \pm 1.71$ & 0.6 & $179.51 \pm 0.91$ & 0.51 & $38.28 \pm 0.77$ & 1.99 \\
\hline
\end{tabular}

A new reversed-phase high performance liquid chromatography method was developed for assay of MET, PIO and VOG in solid dosage form. The validated method was applied for the determination of MET, VOG and PIO in commercially available D-Bose MP275 tablets. The results of assay $(n=3)$ undertaken yielded $101.62 \%(\% R S D=0.01)$ of
MET, $100.38 \%(\%$ RSD=0.3) of PIO and $98.75 \%(\%$ $\mathrm{RSD}=0.35 \%$ ) of VOG. The chromatogram representing the sample is depicted figure 6 and 7 while the result is given in table 6 and 7. All the results found were in good agreement with the label content of marketed formulation.

Table 6: Assay of MET, VOG and PIO in tablet formulation

\begin{tabular}{|c|c|c|c|c|c|c|}
\hline $\begin{array}{c}\text { Sr. } \\
\text { No. }\end{array}$ & Drug & $\begin{array}{c}\text { Conc. } \\
(\boldsymbol{\mu g} / \mathbf{m l})\end{array}$ & Area & Amount found & \% Label claim & \% RSD \\
\hline 1 & MET & 500 & $840.23 \pm 1.32$ & $508.12 \pm 0.65$ & $101.62 \pm 0.13$ & 0.13 \\
\hline 2 & PIO & 75 & $541.24 \pm 2.31$ & $75.28 \pm 0.23$ & $100.38 \pm 0.31$ & 0.43 \\
\hline 3 & VOG & 0.2 & $82.09 \pm 0.5161$ & $0.1975 \pm 0.0007$ & $98.75 \pm 0.3535$ & 0.62 \\
\hline
\end{tabular}

Table 7: Statistical data for estimation of MET, PIO and VOG in marketed formulation

\begin{tabular}{|c|c|c|c|c|c|c|}
\hline \multirow{2}{*}{ Sr. No. } & \multicolumn{2}{|c|}{ MET } & \multicolumn{2}{c|}{ PIO } & \multicolumn{2}{c|}{ VOG } \\
\cline { 2 - 7 } & Assay (mg) & Assay (\%) & Assay (mg) & Assay (\%) & Assay (mg) & Assay (\%) \\
\hline 1 & 508.58 & 101.71 & 75.12 & 100.16 & 0.197 & 98.5 \\
\hline 2 & 507.66 & 101.59 & 75.45 & 100.6 & 0.198 & 99 \\
\hline Mean & 508.12 & 101.62 & 75.28 & 100.38 & 0.1975 & 98.75 \\
\hline SD & 0.65 & 0.12 & 0.23 & 0.31 & 0.0007 & 0.3535 \\
\hline \% RSD & 0.07 & 0.01 & 0.3 & 0.3 & 0.35 & 0.35 \\
\hline
\end{tabular}

The proposed method was found to be linear over selected concentration range. System suitability parameters indicate good resolution for both the peaks $>2$. The method was found to be accurate and precise as indicated by the results of recovery studies and precision studies whose percent relative standard deviation is not more than $2 \%$. There were no marked changes in the chromatograms which confirmed the ruggedness of the method. The standard deviation of \% assay for sample was calculated, for each parameter in robustness studies the relative standard deviation was found less than $2 \%$. The low percent relative standard deviation (\% RSD) value confirms the robustness of method. 


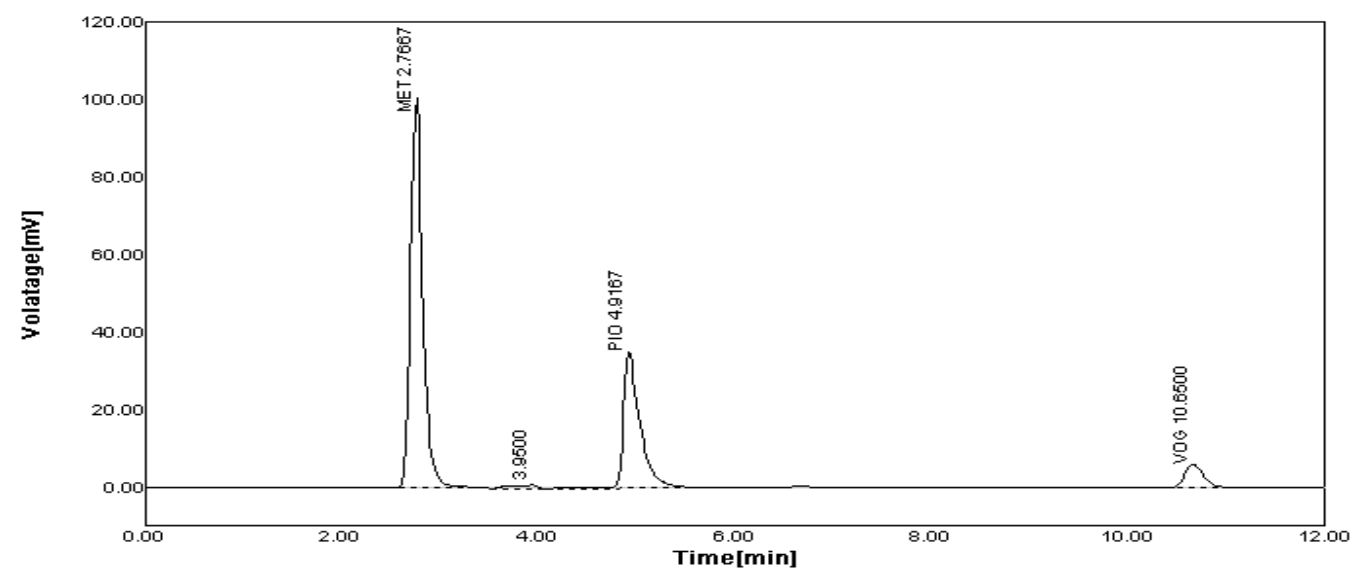

Figure 6: Standard chromatogram of MET, PIO and VOG

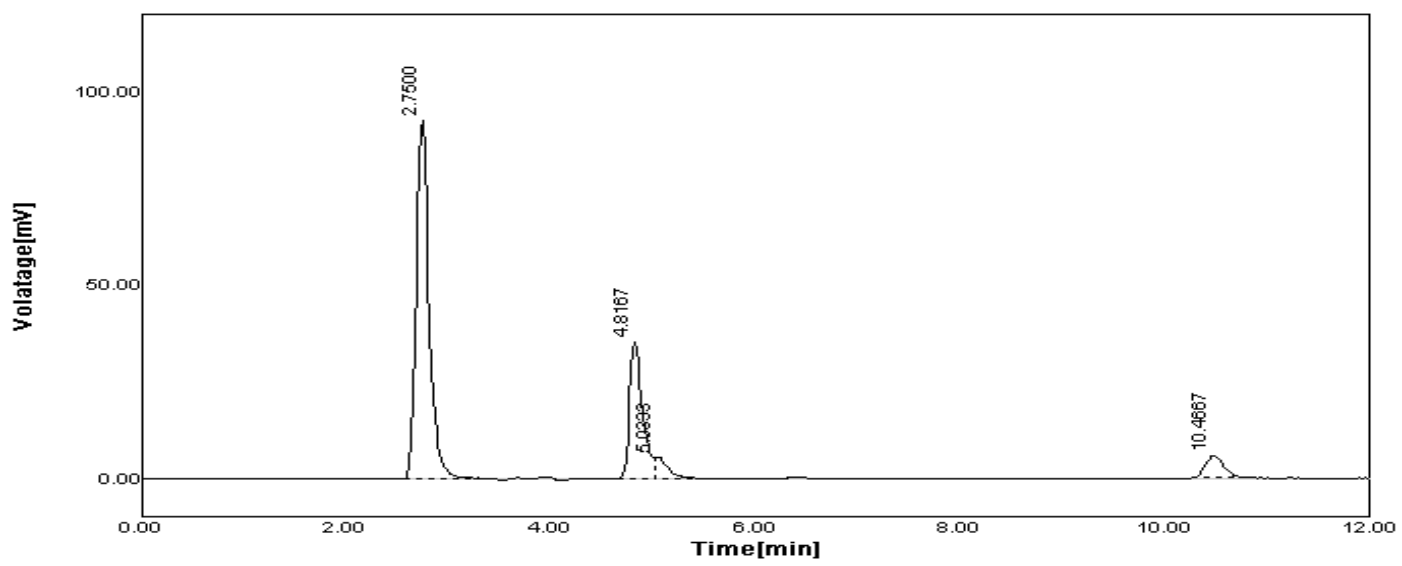

Figure 7: Sample chromatogram of MET, PIO and VOG

The result of analysis of tablets formulation and recovery studies obtained by spectrophotometric method was statistically validated and high percentage of recovery studies suggest that the developed method was free from interferences of excipients generally used in tablet formulation. The developed method was statically validated in terms of accuracy, precision, linearity and reproducibility. Hence, above method can be employed in quality control to estimate the amount of MET, VOG and PIO in bulk and commercial tablets formulation.

\section{CONCLUSION}

Metformin, Voglibose and Pioglitazone were well resolved under optimized chromatographic conditions indicating the selective nature of developed RP-HPLC method. The present developed RP-HPLC method was simple, specific, precise, accurate, and robust, and therefore, it can be applied for the routine quantitative and qualitative including pharmacokinetic studies as well as for the determination of MET, PIO and VOG in pharmaceutical dosage forms.

\section{ACKNOWLEDGMENT}

The authors are grateful to Macloids Pharmaceuticals Ltd (India) for providing the gift samples of the drugs and there is no conflict of interest.

\section{REFERENCES}

1. Sarwar MS, Hossain MD. Fixed dose combination and disease management. Int Res J Pharm, 2012; 3(11):17-21.

2. Meshram DM, Langade DG, Kinagi SB, Naikwadi AA, Morye V, Chopra D. Evaluation of efficacy and safety of fixed dose combination of glimepiride $2 \mathrm{mg}$ pluspioglitazone $15 \mathrm{mg}$ plus metformin SR $500 \mathrm{mg}$ in the management of patients with type-2 diabetes mellitus. Journal of the Indian Medical Association, 2005; 103(8):447-50.

3. Rao C, Faruqui AA. Efficacy and safety of oral triple drug combination (voglibose, glimepiride and metformin) in the management of type 2 diabetes mellitus. Int J Curr Res Rev, 2013; 5:20-6.

4. Jain D, Jain S. Amin M. Simultaneous estimation of metformin hydrochloride, pioglitazone hydrochloride and glimepiride by RP-HPLC in tablet formulation. J Chromatogr Sci, 2008; 46(6):50-504.

5. Kadam VN, Yadav PJ, Mohite SK, Magdum CS. Development and validation of analytical methods for simultaneous estimation of voglibose, glimepiride and metformin hydrochloride in bulk and tablet dosage form by HPLC. Ijppr.Human, 2014; 1(2)1021.

6. Skoog DA, Holler FJ, Nieman TA, Principal of Instrumental Analysis, $5^{\text {th }}$ edition, Thomson Brook, 2005: 674-696.

7. Lakshmi KS, Rajesh T, Sharma S. Simultaneous determination of metformin and pioglitazone by reversed phase HPLC in pharmaceutical dosage forms. Int J Pharm Sci, 2009; 1(2):1626.

8. Sonia K, Babu PK. RP-HPLC analysis of metformin hydrochloride and voglibose and study of its different analytical parameter. Int J Pharm Sci Res, 2013; 1(4):1469-74.

9. Sujana $\mathrm{K}$ et al. Simultaneous estimation of pioglitazone hydrochloride and metformin hydrochloride using UV spectroscopic method. J Biomed Sci Res, 2010; 2(2):110-5.

10. Neha R, Manjula B, Prachi K, Ritu K. Simultaneous quantification of voglibose and metformin by validated analytical method in tablet dosage form. IJPT, 2011; 3(2):53-6.

11. ICH. Topic Q2 (R1) Validation of analytical procedures: Text and methodology, note for guidance on validation of analytical procedures: text and methodology. 1995. (CPMP/ICH/381/95).

12. International Conference on Harmonization. Draft guidance on specifications: Test procedures and acceptance criteria for new drug substances and products: chemical substances, Federal Register (notices) 2000; 65(251):83041-83063. 